\title{
Selecting Effective Influence Principles for Tailoring Gamification-Based Strategies to Player Roles
}

\author{
Simone Borges ${ }^{1,2}$ Seiji Isotani ${ }^{2}$ \\ ${ }^{1}$ Federal University of Technology (UTFPR) - Paraná - PR - Brazil \\ ${ }^{2}$ Institute of Mathematics and Computer Sciences (ICMC) \\ University of São Paulo (USP) - São Carlos - SP - Brazil \\ simoneborges@utfpr.edu.br, sisotani@icmc.usp.br
}

\section{Summary}

Gamification refers to the use of game design elements in contexts other than video games. The primary goal is not fostering playfulness, but to motivate users to perform tasks or change behaviors. However, ill-designed gamification interventions can become a distraction capable of interfering on the teaching-learning process. Despite this, most studies in the area remain focused on the potential benefits of gamification and less on investigating systematized solutions to achieve these benefits. Our contribution to solve the problem is based on the use of persuasion profiles that take into account the student's player roles. We conduct systematic mappings to gather information about gamification in education and group formation (GF) in computer-supported collaborative learning (CSCL). As a result, we created two conceptual frameworks to aid understanding and classifying GF in CSCL and one to support the definition of player roles in CSCL. In a preliminary study $(\mathrm{N}=481)$, we adapted and validated for Brazilian Portuguese speakers a scale to measure users' susceptibility to persuasion. A theoretical model was developed in another study $(\mathrm{N}=140)$ to map persuasive strategies and different roles of players to support the elaboration of persuasion profiles. Finally, the feasibility of our model was tested $(\mathrm{N}=18)$ using prototypes of graphical user interfaces for different players roles. Results would seem to suggest that less motivated students were more likely to accept the suggestions of the prototypes, whereas users with above-average motivation reacted negatively to the attempts of influencing them by showing low agreement rates for the requirements of the prototypes. We also observed in the three studies $(\mathrm{N}=648)$ that the number of individuals susceptible to the principle of authority were the lowest, compared to the other influence principles. Research has shown that gamification models based on one-size-fits-all has the risk of producing counterproductive models that could backfire, since the appropriate strategy to motivate an individual may end up discouraging others. Therefore, evidence would seem to indicate that gamification design could benefit from incorporating influence principles techniques, although tailored solutions should be designed to minimize the risks of selecting counter-tailored and ill-defined persuasive strategies [Borges et al. 2017].

\section{Referências}

Borges, S., Durelli, V., Reis, H., Bittencourt, I. I., Mizoguchi, R., and Isotani, S. (2017). Selecting Effective Influence Principles for Tailoring Gamification-Based Strategies to Player Roles. In Anais do XXVIII Simpósio Brasileiro de Informática na Educação (SBIE 2017), pages 857-866. 